\title{
Objetos de ensino: a renovação pedagógica e material da escola primária no Brasil, no século XX
}

\section{Objects of learning: the pedagogic and material renovation of elementary school in Brazil, in the 20th century}

\author{
Rosa Fátima de Souza ${ }^{1}$
}

\begin{abstract}
RESUMO
O objetivo deste texto é analisar o papel dos objetos de ensino nas proposições de renovação da escola primária durante o século XX assinalando as mudanças na composição material das escolas tendo em vista os objetos que foram introduzidos e ressaltados como relevantes para a modernização da educação e aqueles que permaneceram ou foram redefinidos em termos de finalidades e usos. Pretende-se, dessa forma, examinar três momentos significativos de implantação de inovações na escola elementar: a modernização pelo método intuitivo na virada do século XIX para o século XX, as proposições da Escola Nova nas décadas de 1930 a 1950 e a renovação representada pela Tecnologia Educacional nas décadas de 1960 e 1970.

Palavras-chave: cultura material escolar; objetos escolares; renovação do ensino primário; história da educação; ensino primário.
\end{abstract}

\footnotetext{
ABSTRACT

This article aims at analyzing the role of the objects of learning in the propositions for innovation of primary schools during the 20th century, highlighting the changes in the composition of school subjects having in mind the objects that were introduced and marked out as relevant for school modernization and those that remained or were redefined in terms of their finality and uses. The examination of three significant moments of the implementation

1 Universidade Estadual Paulista "Júlio de Mesquita Filho" (UNESP), Campus de Marília. Av. Hygino Muzzi Filho, no 737, Marília, São Paulo, Brasil. CEP: 17.525-900.
} 
of innovations in the elementary school is intended: the modernization by the intuitive method at the turn of the century; the propositions of "Escola Nova" between the 1930s and the 1950s; and the renovation represented by educational technology in the 1960s and 1970s.

Keywords: school material culture; school objects; renovation of primary school education; history of education; primary school education.

\section{Introdução}

Em 2008, o Ministério da Educação, em parceria com o Ministério da Ciência e Tecnologia, a Rede Latino-americana de Portais Educacionais e outros organismos nacionais e internacionais, criou o Banco Internacional de objetos Educacionais $(\mathrm{BIOE})^{2}$. Integrado ao Portal do Professor ${ }^{3}$, outro ambiente virtual de pesquisa e interatividade criado pelo Ministério, esse repertório é justificado pela finalidade de disponibilizar recursos pedagógicos, explorando ferramentas da tecnologia da informação e da comunicação de modo a favorecer o trabalho docente e possibilitando o enriquecimento da prática educativa. De certa forma, essa iniciativa do governo federal integra o conjunto das políticas educacionais contemporâneas levadas a termo pelos poderes públicos de vários estados brasileiros, subsidiados com financiamento de organismos internacionais e associadas a interesses econômicos específicos, de investimento em materiais didáticos, técnicas e novas tecnologias apresentadas como meios auxiliares do ensino capazes de melhorar a qualidade da educação no país. Essa ênfase atribuída aos objetos didáticos como meios potenciais para a qualificação da escola e melhoria das condições de trabalho dos professores reatualiza, de certa forma, práticas discursivas e políticas que nos últimos dois séculos têm reincididamente vinculado a adoção de novas tecnologias e materiais escolares a proposições de renovação educacional.

Vista da perspectiva histórica, pode-se dizer que a relação entre materiais escolares e renovação pedagógica consolidou-se no ensino primário especialmente a partir do século XIX quando, em vários países do ocidente, foram experimentadas novas modalidades de organização da escola elementar visando à universalização do ensino.

2 Cf. http://objetoseducacionais.mec.gov.br Acesso em: 01/04/2012.

3 Cf. Portal do Professor: http://portaldoprofessor.mec.gov.br Acesso em: 01/04/2012. 
O propósito deste texto é analisar o papel dos objetos de ensino nas proposições de renovação da escola primária durante o século $\mathrm{XX}$, assinalando as mudanças na composição material das escolas tendo em vista os objetos que foram introduzidos e ressaltados como relevantes para a modernização da educação e aqueles que permaneceram ou foram redefinidos em termos de finalidades e usos. Pretende-se, dessa forma, examinar três momentos significativos de implantação de inovações na escola elementar: a modernização pelo método intuitivo na virada do século XIX para o século XX, as proposições da Escola Nova nas décadas de 1930 a 1950 e a renovação representada pela Tecnologia Educacional nas décadas de 1960 e 1970. De modo mais específico, a análise incide sobre os suportes materiais do ensino, ou seja, os objetos utilizados por professores e alunos nas escolas em situações de ensino e aprendizagem ${ }^{4}$.

Ao privilegiarmos a relação entre os objetos escolares e a renovação do ensino, não estamos desconsiderando a rede complexa de relações em que a cultura material escolar encontra-se imersa. No entanto, o recorte temático adotado neste texto privilegia a relação entre a cultura material e o currículo. Evidentemente, trata-se de outra entrada para se abordar o problema da transmissão cultural da escola que historicamente tem envolvido não somente a seleção de conteúdos e métodos, mas também os suportes materiais considerados necessários para a concretização do ensino (SOUZA, 2007).

\section{Lições de coisas: os objetos como fundamentos da educação moderna}

A centralidade dos objetos na educação dos sentidos consistiu em um dos principais pressupostos do método intuitivo, considerado o ícone da escola moderna no final do século XIX. Também denominado de lições de coisas e ensino pelos aspectos, o método tornou-se uma importante matriz discursiva no processo de internacionalização da educação nesse período.

4 A definição e a classificação desses objetos consistem em desafios a serem enfrentados pelos pesquisadores dedicados ao estudo da cultura material da escola. É necessária a construção de uma genealogia dos termos. Por exemplo, na documentação da instrução pública do estado de São Paulo referente ao final do século XIX e início do século XX é frequente o uso dos termos material, instrumentos de ensino e objetos escolares para designar livros, mapas, quadros, lousas, tinta, canetas, entre outros objetos empregados no ensino das matérias do curso primário. A referência a termos como materiais didáticos, recursos auxiliares do ensino, materiais pedagógicos, meios materiais, entre outros, tornou-se mais comum em meados do século XX, submetidos, ao que tudo indica, a uma tematização do campo pedagógico, especialmente da Didática, como mostra o estudo de Fiscarelli (2008). 
Como assinala Valdemarin (2004a), na proposição do método intuitivo a observação e os objetos foram considerados instrumentos indispensáveis para auxiliar na passagem das percepções às ideias. Dado que o conhecimento do mundo material era derivado dos sentidos, cabia à escola colocar as crianças em contato com os objetos. As lições de coisas deveriam partir, portanto, dos objetos familiares à criança, ampliando do conhecido para o desconhecido. Nesse procedimento de apreensão do mundo sensível, a escola deveria explorar a forma, as propriedades, as características e a utilidades dos objetos, desenvolvendo nas crianças a capacidade de lidar com a modernidade. Para a autora, os objetos adquirem tanta importância na proposição do método de ensino intuitivo porque a disseminação do mesmo coincide com o momento em que os objetos materiais são produzidos e industrializados e vistos como símbolos de civilização.

Entende-se, desse modo, como se tornou imperiosa a necessidade de materiais didáticos para a adoção do método intuitivo e porque ocorreu uma proliferação vertiginosa de objetos industrializados para uso nas escolas a partir de meados do século XIX. Nesse processo, não podemos deixar de mencionar o importante papel desempenhado pelas exposições pedagógicas realizadas no interior das Exposições Universais na difusão e circulação dessas inovações materiais ${ }^{5}$.

No Brasil, o método de ensino intuitivo começou a ser divulgado por volta de 1870 , mas foram as reformas da instrução pública levadas a termo em vários estados do país nas primeiras décadas republicanas que possibilitaram sua adoção oficial e sua institucionalização nas escolas públicas primárias.

No estado de São Paulo, os primeiros governos republicanos assumiram a responsabilidade pela dotação material das escolas elementares em conformidade com o ideário de modernização do ensino. Muitos materiais foram importados, incluindo bancos-carteiras e objetos para as lições de coisas: cartas de Parker, modelos de Prang, museu Deyrolle, museu Safray, tornos mecânicos, peças anatômicas, aparelhos de física e química, mapas geográficos, mapas de história natural e do sistema de pesos e medidas, entre outros. Contudo, a dotação material para a rede pública de ensino foi muito heterogênea. Somente as escolas-modelo

5 Conforme relato de F. Buisson (1875), a Exposição de Paris de 1855 foi a primeira a abrir uma divisão especial para o material do ensino elementar. Nessa exposição foram apresentados instrumentos e aparelhos para o ensino da geografia, do desenho e das ciências físicas e naturais. Essas coleções figuraram exclusivamente como produtos da indústria. Na Exposição Universal de Londres, realizada em 1862, foi consagrada, pela primeira vez, uma classe especialmente destinada à educação para exposição dos progressos do ensino de diferentes países. A Exposição de Paris em 1867 atribuiu lugar de destaque à educação popular, colocando em evidência as escolas primárias e profissionais, os cursos de adultos e as bibliotecas rurais. Nessas Exposições e nas subsequentes foi usual o julgamento, classificação e premiação de obras e materiais escolares inseridos no grande espetáculo da indústria. Dentre as várias pesquisas realizadas sobre a educação nas exposições universais, cf. Kuhlmann Jr. (2001). 
e alguns grupos escolares puderam contar com abundante e diversificado material de ensino em consonância com as inovações em circulação na transição do século XIX para o século XX. Mas a rigor, predominou a precariedade e a falta de objetos - motivo de queixa permanente de professores e diretores de escolas ao longo do século XX (SOUZA, 1998, 2004).

A ampliação da composição material das escolas primárias resultou não apenas dos novos métodos pedagógicos, mas também da diversificação e abrangência dos programas de ensino. A reforma da instrução pública realizada em São Paulo no final do Império (Lei no 81, de 6 de abril de 1887) estabeleceu um programa abrangente, compreendendo educação cívica, leitura e princípios de gramática, escrita e caligrafia, noções de geografia geral, geografia do Brasil, especialmente do estado de São Paulo, cálculo aritmético sobre os números inteiros e frações, sistema métrico decimal, noções de geometria, especialmente nas suas aplicações à medição de superfície e volumes, noções de ciências físicas, químicas e naturais nas suas mais simples aplicações, especialmente à higiene, desenho a mão livre, canto e leitura de música, exercícios ginásticos apropriados à idade e ao sexo. A reforma republicana de 1892 (Lei n ${ }^{\circ} 88$, de 8 de setembro de 1892) manteve esse rol de conteúdos e acrescentou moral prática, cosmografia, história do Brasil e leitura sobre a vida dos grandes homens da história e exercícios manuais e militares.

O ensino de todas essas matérias pelo método intuitivo demandava, por sua vez, uma grande quantidade de materiais.

A expansão contínua da rede de escolas primárias no estado de São Paulo nas primeiras décadas do século XX ocorreu por um processo de múltiplas diferenciações. Além dos diferentes tipos de escolas existentes - escolas isoladas, grupos escolares, escolas modelos, escolas reunidas -, as condições de instalação e material se diferenciaram pela localidade onde elas estavam instaladas, se na zona urbana ou rural, dependendo ainda do desenvolvimento econômico e social regional. A partir da década de 1920, por medidas econômicas, os governos do estado de São Paulo foram aos poucos restringindo a dotação material para as escolas, limitando-se à manutenção do mobiliário indispensável, livros, cartilhas e alguns poucos objetos de ensino.

A falta de materiais tornou-se uma justificativa recorrente dos professores para justificarem a impossibilidade de adoção do método intuitivo ou a sua aplicação parcial. Passado o entusiasmo inicial pela pedagogia moderna, consagrou-se nas escolas primárias o uso sistemático das cartilhas e livros de leitura e as lições rotineiras empregando o quadro negro e giz, cadernos e lápis. $\mathrm{Na}$ maioria das escolas, os objetos de ensino mais comumente encontrados continuaram a ser os mapas e cartazes. A partir dos anos vinte do século XX, o discurso pedagógico deixaria de enfatizar a relevância de se colocar as crianças 
em contato com os objetos representativos do avanço científico e industrial visando à educação dos sentidos. As novas concepções educacionais passaram a ressaltar a necessidade de adaptar a escola ao meio social, preparando as novas gerações para viverem em uma civilização em mudança, o que implicava, entre outros aspectos, a adoção de novas tecnologias.

\section{Escola Nova: os objetos como mediadores da experiência e da atividade}

As diferenças nas concepções de conteúdo e método de ensino entre as proposições do Método Intuitivo e da Escola Nova foram analisadas com profundidade por Vera Valdemarin (2004b). De acordo com a autora, como mencionamos anteriormente, uma das inovações vinculadas ao método de ensino intuitivo foi a consideração dos objetos como primordiais no processo de aquisição do conhecimento. Contudo, na pedagogia da Escola Nova, tomando como referência o pensamento de John Dewey, o objeto como ponto de partida das ideias foi substituído pelo problema, isto é, o conhecimento resultava da indagação geradora da reflexão que partia da experiência do aluno. Uma das implicações desse deslocamento está no papel secundarizado atribuído ao professor no processo de transmissão cultural. A autora esclarece ainda que, no método de ensino intuitivo, os objetos e as coisas "introduzidas na escola como objetos didáticos, tinham forte vínculo com a produção social e com a aplicação do conhecimento científico", entretanto, na proposição deweyniana da Escola Nova, o problema "guarda forte relação com a percepção do próprio indivíduo sobre a sociedade na qual ele se insere, percepção essa que depende das experiências já vivenciadas" (VALDEMARIN, 2004b, p. 193).

No método intuitivo, a seleção dos objetos, mesmo guardando relações com a infância, resultava de uma escolha do adulto. Na Escola Nova, os objetos de ensino são recursos auxiliares que devem ser disponibilizados pela escola para favorecer a atividade do aluno. Portanto, na pedagogia nova, os objetos de ensino perdem a centralidade adquirida na renovação pelas lições de coisas. Eles deixam de ser condição para a aquisição do conhecimento e se convertem em meios, componentes de um ambiente deliberadamente organizado para fomentar experiências de aprendizagem. Justifica-se, dessa maneira, a necessidade de laboratórios, oficinas, salas ambiente, museus, bibliotecas, hortas, jardins, auditórios e quadras de esportes, ou seja, a diversificação de espaços e materiais para a prática de múltiplas atividades de observação e experimentação do meio incluindo jogos, brincadeiras e dramatizações (VALDEMARIN, 2009). 
No Brasil, a Escola Nova tornou-se o ideário de renovação do ensino primário a partir da década de 1920 . No final dessa década e no início dos anos 30 , vários estados brasileiros promoveram reformas educacionais com base na moderna pedagogia que propunha, para além de mudanças metodológicas no ensino, novas finalidades para a educação, associando a escola aos projetos de modernização e reconstrução social do país. Dois aspectos marcaram a renovação educacional pela Escola Nova: a denominada escola ativa, envolvendo formulações como a globalização do ensino, a adoção dos centros de interesse, os métodos ativos, a ênfase em atividades como excursões, salas ambiente, método de projetos, etc., e as instituições auxiliares da escola. É no interior dessas inovações que se pode compreender os novos significados atribuídos aos objetos de ensino e à reconfiguração material das escolas primárias (SOUZA, 2009).

Para os renovadores da Escola Nova no Brasil - educadores e intelectuais que se dedicaram a publicizar os princípios da pedagogia moderna por meio de diferentes estratégias, como Fernando de Azevedo, Lourenço Filho, Anísio Teixeira, Carneiro Leão, Mário Casassanta, entre outros - a reorganização radical do sistema educacional brasileiro passava não apenas pela mudança dos métodos pedagógicos, mas, também, pela finalidade social da escola. Por um lado, cabia a ela adaptar as crianças às necessidades da sociedade moderna, entendida como uma civilização em mudança; por outro lado, ela deveria constituir-se em elemento transformador do meio social, abrindo-se à comunidade e intervindo nos processos sociais. Dessa maneira, era justificada a relevância das instituições auxiliares da escola - bibliotecas, museus, cooperativas, associações de pais e mestres, caixa escolar, clubes de leitura, assistência médica e dentária, pelotões de saúde, ligas de bondade, entre outras -, e a adoção de um aparelhamento escolar mais sofisticado, incorporando inclusive as novas tecnologias da comunicação. Esse entendimento da escola como instituição social foi claramente defendida no Manifesto dos Pioneiros da Educação Nova:

As instituições periescolares e postescolares, de caráter educativo ou de assistência social, devem ser incorporadas em todos os systemas de organização escolar para corrigirem essa insufficiencia social, cada vez maior, das instituições educacionaes. [...] a escola deve utilizar, em seu proveito, com a maior amplitude possível, todos os recursos formidáveis, como a imprensa, o disco, o cinema e o radio, com que a sciencia, multiplicando-lhe a efficacia, acudiu á obra de educação e cultura e que assumem, em face das condições geográficas e da extensão territorial do paiz, uma importância capital (MANIFESTO..., 1984, p. 423). 
No ideário renovador, a materialidade da escola e os objetos de ensino adquirem novos significados devido às concepções educacionais que redefinem o papel da escola e dos conteúdos, sustentando outras interpretações sobre o processo de ensino-aprendizagem. A introdução de novas tecnologias e materiais escolares esteve diretamente associada às instituições auxiliares pelo fato de se constituírem em condições para o funcionamento de muitas delas.

O caso da introdução dos aparelhos de projeção fixa e animada e do cinema educativo é interessante. A educação pela imagem utilizando equipamentos modernos atendia o princípio do interesse da criança, da atividade motivada e da possibilidade de aquisição de conhecimentos por meios que reagiam contra o verbalismo e a memorização. As novas tecnologias coadunavam com o espírito que informava os pressupostos da Escola Nova, isto é, a educação orientada para a vida moderna, aberta a novos horizontes e concebendo o conhecimento como um processo de aquisição mais flexível, mais ampliado e diversificado. O cinema educativo começou a ser divulgado no Brasil desde o início do século XX. Mas foi com a difusão da Escola Nova que ele se propagou mediante várias iniciativas levadas a termo pelos governos federal e estaduais. Em 1928, Fernando de Azevedo implementou o cinema educativo no Distrito Federal como inovação pedagógica no âmbito da reforma da instrução pública. Em 1937, foi criado pelo governo de Getúlio Vargas o Instituto Nacional de Cinema Educativo (I. N. C. E.). No estado de São Paulo, o Serviço de Cinema Educativo foi criado em 1931 por Lourenço Filho. Posteriormente, em 1933, mediante o Código de Educação, essa secção foi ampliada e regulamentada pelo Serviço de Rádio e Cinema Educativo (MONTEIRO, 2006).

As bibliotecas pedagógicas (para uso dos professores) e as bibliotecas infantis também foram muito enfatizadas, vistas como elementos primordiais para o aperfeiçoamento da leitura, como instrumento auxiliar dos estudos à medida que propiciavam fontes de informação e como meios para despertar, desenvolver e manter o gosto pela leitura.

Museus, laboratórios e gabinetes devidamente equipados haveriam de enriquecer a composição material das escolas, atendendo as exigências da aprendizagem pela experiência, pela observação e pela investigação. Como observa Vidal (1994), os museus deixavam de ser meras coleções de objetos para se tornarem uma espécie de laboratório onde as crianças entrariam em contato com as ciências.

Vários equipamentos e aparelhos foram associados ao movimento renovador. Essa nova composição material das escolas primárias foi objeto de interesse dos primeiros levantamentos realizados pelo Instituto Brasileiro de Geografia e 
Estatística (IBGE) sobre a estatística educacional na década de 1930, visando a esclarecer as condições do ensino ministrado no país ${ }^{6}$.

No ano de 1937, o Brasil contava com 37.011 estabelecimentos de ensino primário (44 federais, 17.924 estaduais, 11.554 municipais e 7.489 particulares) com 2.910.441 alunos matriculados. Desse contingente, havia 3.785 alunos no ensino primário público federal, 1.688 .323 no estadual (58\%), 676.259 no municipal $(23,2 \%)$ e $545.074(18,6 \%)$ no ensino particular. Desse número de alunos, $48,8 \%$ encontravam-se matriculados nas sedes dos municípios (zona urbana), $14,4 \%$ em distritos e $36,8 \%$ na zona rural $^{7}$.

Do número total de estabelecimentos de ensino primário existentes nesse ano, apenas $2.263(6,04 \%)$ contavam com bibliotecas para professores, 2.928 (7,9\%) com bibliotecas para alunos, $1.102(2,9 \%)$ estabelecimentos possuíam museus e $660(1,7 \%)$ laboratórios e gabinetes. A maior parte desses equipamentos encontrava-se em estabelecimentos de ensino localizados no Distrito Federal, Minas Gerais, Rio Grande do Sul e São Paulo.

Em se tratando de equipamentos para projeções luminosas, trabalhos manuais e educação física, insistentemente apresentados como imprescindíveis para a moderna pedagogia, a situação de precariedade material das escolas primárias brasileiras era notável. Em 1937, em todo o país, havia somente 351 equipamentos para projeções luminosas fixas e 542 para projeções luminosas animadas. As escolas que possuíam equipamentos para trabalhos manuais eram em número de 2.110 , equipamentos para a educação física 2.118 e para trabalhos práticos de agricultura 982 estabelecimentos.

O desenvolvimento das instituições auxiliares da escola era bastante incipiente. Os dados nacionais indicavam a presença maior de algumas instituições como clubes de leitura (970 estabelecimentos), auditórios (950), Associações de Pais e Mestres (627) e Caixas Escolares (2.347), a mais bem sucedida de todas.

Para além desse aparelhamento, outros objetos passaram a ser utilizados nas escolas tendo em vista as práticas do ensino ativo. Os álbuns diários individuais e da classe, brinquedos, jogos, calendários, diafilmes, diapositivos,

${ }^{6}$ O Convênio Estatístico para o aperfeiçoamento e uniformização das estatísticas educacionais e anexas foi firmado em 1931 pelo Ministério da Educação e Saúde e o Instituto Brasileiro de Geografia e Estatística. Os resultados nacionais do ensino foram publicados em volumes referentes a vários anos letivos da década de 1930, trazendo informações detalhadas sobre a organização do ensino (número de estabelecimentos, prédios, pessoal, aparelhamento e instituições escolares), organização didática e movimento escolar (matrícula geral e efetiva, frequência média, conclusões de curso, número de turnos e classes de funcionamento das escolas e corpo docente) de cada nível de ensino em âmbito nacional e regional. Cf. Brasil (1943).

7 Esses e os demais dados assinalados em relação ao ano de 1937 encontram-se na publicação do Ministério da Educação e Saúde intitulada O Ensino no Brasil em 1937. Cf. Brasil (1943). 
gravuras, aquários, tabuleiros de areia, etc. Ao uso de tecnologias foram agregados materiais de uso social, introduzidos nas escolas como auxiliares do ensino, e outros produzidos pelos próprios professores. No entanto, de acordo com o ideário renovador, o mais importante na seleção e uso dos materiais era a potencialidade apresentada por eles para estimular a atividade e o interesse da criança e favorecer experiências de aprendizagem.

No estado de São Paulo, o ideário da Escola Nova tornou-se a orientação oficial do ensino primário nas décadas de 1930 e 1940. Entre 1930 e 1937, passaram pela direção do ensino do estado nomes expressivos do movimento escolanovista brasileiro como Lourenço Filho, Fernando de Azevedo, Antonio Ferreira de Almeida Junior, entre outros. Em 1933, Fernando de Azevedo coordenou a elaboração do Código de Educação do Estado de São Paulo (Decreto n ${ }^{0} 5.884$, de 21 de abril de 1933), instrumento normativo que consolidou os princípios da escola nova na educação paulista por quase três décadas (SOUZA, 2009, 2011).

Tudo indica que no início dos anos 30 do século XX, apesar da orientação oficial dos princípios da Escola Nova, o Poder Público do estado de São Paulo encaminhava às escolas o mínimo necessário para as atividades de leitura e escrita. No estudo realizado por Souza (2009) sobre as práticas de ensino renovadoras nas escolas paulistas no período de 1930 a 1960 foi constatado que poucas escolas contavam com projetores para projeção fixa e animada, rádio educativo, bibliotecas escolares e outros materiais indicados na época como inovadores. A introdução desses melhoramentos, quando ocorria, devia-se menos à intervenção do Estado e mais à boa vontade da comunidade escolar, mediante doações ou campanhas para aquisição de recursos para a compra dos mesmos.

A questão de saber em que medida foram alteradas as condições materiais das escolas primárias paulistas pela influência da renovação pedagógica pela escola nova depende de investigações sistemáticas sobre os inventários de bens materiais existentes em acervos escolares e os usos que os professores faziam dos objetos de ensino. Entretanto, resultados de pesquisa realizada no final dos anos 50 sobre o tema pela Divisão de Estudos e Pesquisas Sociais do Centro Regional de Pesquisas Educacionais de São Paulo (CRPE/SP) oferecem alguns dados reveladores.

O relatório de pesquisa de 1960, intitulado Levantamento do Ensino Primário $^{8}$, buscou avaliar o desenvolvimento dos aspectos materiais e as instituições

8 O projeto de pesquisa Levantamento do Ensino Primário no Estado de São Paulo foi proposto pela Divisão de Estudos e Pesquisas Sociais do Centro Regional de Pesquisas Educacionais de São Paulo em 1956. A investigação incidiu sobre as escolas públicas primárias da cidade de São Paulo, e foram utilizados como fontes de pesquisa os dados coligidos pelo Departamento 
auxiliares do ensino elementar do município de São Paulo tomando como base o período de 1930 a 1957, considerado pela equipe de pesquisadores do CRPE/ SP como um período de renovação do ensino primário nas escolas públicas pela introdução de várias inovações no sistema educacional.

Nos dados coligidos pelos pesquisadores do CRPE/SP sobre as condições materiais das escolas foram levados em consideração três aspectos: 1) as instalações, compreendendo a rede de prédios escolares; 2) o equipamento didático envolvendo as bibliotecas e os recursos audiovisuais; 3 ) as instituições auxiliares agrupadas em conformidade com as funções exercidas nas escolas, isto é, instituições culturais, assistenciais e sociais. Para os investigadores, esses três aspectos abarcavam em grande medidas as necessidades materiais pressupostas nas proposições escolanovistas.

No que diz respeito aos objetos de ensino, a pesquisa apresentou dados sobre as bibliotecas e os recursos audiovisuais (cinema, projetores, vitrola, etc.) considerados pelos pesquisadores do CRPE/SP como as principais inovações introduzidas no equipamento didático das escolas primárias paulistas entre as décadas de 1930 e 1950. De acordo com a investigação, em 1937, havia 155 bibliotecas para alunos em estabelecimentos de ensino primário na Capital e, em 1957, havia 411. Esses dados indicavam que "[...] a criação de bibliotecas, depois de um surto no período de 30-37, não mais se expandiu e que o seu uso, como auxiliar do ensino de classe, é aleatório não sistemático." (LEVANTAMENTO..., 1960, p. 69).

O termo audiovisual vinha se propagando no Brasil desde o final dos anos 50, referindo-se a recursos utilizando imagem e som. Isso explica por que os pesquisadores do CRPE/SP avaliaram os objetos de ensino relacionados à escola nova como recursos audiovisuais. Em realidade, tratava-se daqueles equipamentos que foram vinculados desde os anos 30 ao movimento renovador.

De acordo com o quadro a seguir, os objetos mais encontrados nas escolas da Capital eram mapas e cartazes, adotados de longa data e associados à escola tradicional. Já os recursos ligados ao movimento de renovação educacional como vitrolas, projetores e modelos existiam em menor número, indicando a pequena contribuição desses recursos propalados para a renovação didática.

de Estatística do Estado de São Paulo e estimativas obtidas a partir de amostra - questionários aplicados a um determinado conjunto de escolas. Essas informações e a descrição detalhada desse projeto foram publicadas na revista Pesquisa e Planejamento, v. 1, n. 1, 1957. Maiores informações sobre as pesquisas realizadas pelo CRPE/SP podem ser encontradas no estudo de Ferreira (2001). 
TABELA 1 - EQUIPAMENTO DIDÁTICO DAS ESCOLAS PRIMÁRIAS DA CAPITAL (SÃO PAULO), 1957

\begin{tabular}{|l|l|}
\hline & Escolas* \\
\hline Mapas & 586 \\
\hline Cartazes & 446 \\
\hline Vitrolas & 210 \\
\hline Projetores & 167 \\
\hline Modelos & 167 \\
\hline Nenhum recurso áudio-visual & 23 \\
\hline Número de escolas & 627 \\
\hline
\end{tabular}

FONTE: Levantamento (1960, p. 70).

Por último, em se tratando das instituições auxiliares da escola, a pesquisa demonstrava que entre as instituições culturais, cuja função era complementar o ensino de classe, preponderavam atividades ligadas ao cinema, biblioteca, vitrola, jornal e orfeão. Entre todas essas atividades, a mais frequentemente encontrada foi o jornal escolar, o que poderia ser explicado pelo fato de não necessitarem de equipamento especial de custo elevado para a sua publicação, possibilitando, assim, maior receptividade do magistério. Entre as instituições assistenciais, a caixa escolar era a mais presente nas escolas, seguida das instituições de assistência alimentar (sopa, lanche, leite). As instituições sociais - associação de pais e mestres, cooperativa escolar e atividades voltadas para o tratamento de jardins, hortas e animais - tinham a função de desenvolver no educando hábitos, interesses e atitudes socialmente valorizadas, promovendo a integração entre escola e sociedade. Nas escolas primárias da Capital, essas instituições tiveram pouco desenvolvimento. A maior receptividade foi em relação à Associação de Pais e Mestres, que se encontrava em funcionamento em um terço das escolas. Em síntese, os resultados do levantamento das condições materiais dos estabelecimentos de ensino primário da Capital paulista apontavam para a seguinte conclusão: “As novas práticas educacionais, advogadas pelo movimento renovador de nossa educação, não se integram[vam] no sistema escolar primário do município de São Paulo (LEVANTAMENTO..., 1960, p. 79).

Certamente, a ausência de materiais inovadores não foi o único nem o principal fator responsável pelas dificuldades de adoção dos princípios da escola nova na rede estadual paulista. Mas ela atesta, sem dúvida, mais uma vicissitude da renovação preconizada. 


\section{Tecnologia Educacional: as promessas de eficiência dos recursos audiovisuais}

Nas décadas de 1960 e 1970, sob a égide da Tecnologia Educacional, novas tecnologias de ensino e materiais didáticos estiveram no centro das proposições de modernização da educação no Brasil. Especialmente nos recursos audiovisuais, supervalorizados nesse período, foram depositadas as expectativas de renovação didática. Em realidade, inicialmente, o próprio termo "tecnologia educacional" foi concebido como a utilização de equipamentos audiovisuais e outros recursos tecnológicos com fins educacionais. No entanto, o conceito foi se redefinindo tendo em vista a abrangência que a abordagem passou a ter, aplicando conhecimentos científicos fundamentados na psicologia da aprendizagem, na teoria da comunicação e na teoria sistêmica na solução de problemas educacionais.

Apresentada pelos seus propugnadores como um "movimento", estratégia discursiva empregada visando a validar e legitimar a abordagem no campo da educação, a Tecnologia Educacional difundiu-se no Brasil a partir da década de 1950 em grande parte patrocinada pela atuação do Ministério da Educação e Cultura em convênio com organismos internacionais norte-americanos.

O êxito dessa concepção na educação brasileira deve-se em parte a esse apoio do Poder Público, mas deve ser creditada também à congruência com as representações educacionais em voga na época, isto é, a relação entre educação e desenvolvimento nacional e as promessas de modernização do ensino.

De fato, como analisou Lucíola Santos (1980), uma das características fundamentais da Tecnologia Educacional foi o seu embasamento em conhecimentos científicos que possibilitaram a essa abordagem se estabelecer pelos critérios de objetividade e neutralidade. A ênfase no planejamento, economia e administração da educação, por sua vez, apontava as necessidades de incrementar a eficiência nos sistemas educacionais dos países subdesenvolvidos, possibilitando a aceleração do desenvolvimento econômico e social (HORTA, 1982). Ainda, de acordo com a autora, outro aspecto importante dessa concepção foi a noção de "tecnologia" que permitiu vincular as atividades educativas ao desenvolvimento atingido pelas sociedades modernas.

Em realidade, um dos desdobramentos dessa abordagem foi a construção de saberes específicos sobre a utilização dos objetos de ensino na educação, alçando-os como temática relevante no campo pedagógico (FISCARELLI, 2009).

No âmbito da Tecnologia Educacional, os materiais escolares foram redefinidos em sua concepção, materialidade, finalidades e usos. Todas as atenções 
se voltaram para os recursos audiovisuais, considerados meios mais efetivos para modernizar a prática educativa e atualizar a educação em consonância com os avanços tecnológicos da época, especialmente a disseminação dos meios de comunicação de massa. Como explica Fiscarelli (2009), o termo audiovisual entrou no campo pedagógico a partir do discurso que aliava imagens e sons a serviço do ensino. Designava, pois, tanto os métodos e técnicas, quanto os objetos que as concretizavam. Referia-se às tecnologias sofisticadas, como os programas de teleducação e rádio educativo, e aos objetos didáticos mais simplificados: álbum-seriado, folhetos, flanelógrafos, gráficos, cartazes, diafilmes, diapositivos, filmes, exposições, rádio, imprensa, quadro-negro, fantoches, jornal de parede, dioramas, modelos, espécimes, sistema de alto-falante, jornal, revistas, dobradura, retroprojetor, mapas-relevo, fotografia, livro, hectógrafo, entelagem, pantógrafo, desenho, mural didático, figuras e ilustrações.

Em consonância com a fundamentação científica almejada pela Tecnologia Educacional, os recursos audiovisuais foram alvo de inúmeras reflexões teóricas. Parte dessa produção buscou fundamentar as vantagens desses recursos na Psicologia tendo em vista o desenvolvimento infantil, as questões pertinentes à aprendizagem e à motivação. Outros textos buscaram avaliá-los a partir das políticas educacionais e, alguns, os problematizaram no campo da Didática submetendo-os à classificação, a propostas metodológicas de uso em sala de aula e ao exame em termos de sua contribuição para a melhoria do ensino?.

O balanço realizado por Letícia Faria (1976) sobre a situação dos audiovisuais no Brasil em meados da década de 1970 possibilita dimensionar a difusão que eles tiveram no período e a intervenção dos poderes públicos em sua promoção no campo educacional. Segundo a autora, o Governo Federal, através do Plano Setorial de Educação e Desenvolvimento Científico, suplementava a ação dos governos estaduais que vinham promovendo a assistência técnica e o apoio financeiro a instituições oficiais e particulares que realizavam projetos envolvendo produção e uso de recursos audiovisuais educativos. O Ministério do Planejamento e Coordenação Geral promovia diagnósticos nacionais de Rádio, Cinema e Televisão Educativa. Além dessas iniciativas, a autora assinalava a existência de vários Centros e Serviços de Audiovisuais no país mantidos por particulares ou pelos poderes públicos e outros integrados a instituições mais

9 Ver, a título de exemplo dessa produção didática, Parra (1974). A produção bibliográfica sobre recursos audiovisuais e Tecnologia Educacional é muito vasta. Em 1976, a Revista Brasileira de Estudos Pedagógicos, em um número dedicado exclusivamente a esse tema, publicou uma compilação de referências bibliográficas sobre o assunto existentes no país. Cf. Bibliografia (1976). Vale citar, ainda, o estudo aprofundado de Fiscarelli (2009) sobre a construção do saber sobre a utilização de objetos no ensino brasileiro, tomando como fonte de análise dois periódicos: Audiovisual em Revista e Tecnologia Educacional. 
amplas de educação e ensino ou de pesquisa educacional. Entre as principais instituições de estímulo à produção e uso de recursos audiovisuais no Brasil a autora destacou: os Centros ou Serviços Audiovisuais das Universidades, Secretarias de Educação e de estabelecimentos de ensino de diferentes níveis e localidades, o Instituto Nacional de Cinema, os Serviços Cinematográficos do Exército, Marinha e Aeronáutica, o Serviço de Cinema do Ministério da Agricultura, o Serviço Cartográfico do Instituto Brasileiro de Geografia e Estatística, Fundação Nacional do Material Escolar, Fundação Centro Brasileiro de Televisão Educativa, Centros ou Serviços Audiovisuais de instituições como a Superintendência de Desenvolvimento da Amazônia (SUDAM), a Superintendência do Desenvolvimento do Nordeste (SUDENE) e Superintendência do Desenvolvimento da Região Sul (SUDESUL), Laboratórios de Línguas, Museus do Departamento de Cultura do Ministério de Educação e Cultura, emissoras educativas de Rádio e Televisão em circuito aberto e em funcionamento nos diversos estados brasileiros.

Vemos, desse modo, como foi forte o incentivo à adoção e uso dos recursos audiovisuais na educação brasileira nas décadas de 1960 e 1970. As políticas educacionais implementadas pelos poderes públicos em âmbito federal e estadual apoiaram projetos ambiciosos envolvendo o uso de tecnologias avançadas e de alto custo como o Projeto Minerva - a utilização do rádio na área de ensino supletivo - e o Programa Nacional de Teleducação (PRONTEL) (HORTA, 1973). Entretanto, o pensamento educacional renovador nesse período enfatizou muito os recursos audiovisuais acessíveis às escolas e aos professores. Em realidade, uma das estratégias de legitimação do movimento foi justamente apresentar as novas tecnologias e os recursos audiovisuais como imprescindíveis e plenamente factíveis.

No estado de São Paulo, vestígios da adoção da Tecnologia Educacional no ensino primário podem ser identificados com o conjunto de medidas inovadoras adotado pela Secretaria do Estado da Educação, com base nas orientações do Programa de Assistência Brasileira-Americana ao Ensino Elementar (PABAEE), e na atuação do Centro Regional de Pesquisas Educacionais. O PABAEE compreendia um acordo entre Brasil e Estados Unidos, assinado em 1956, visando ao treinamento de supervisores, professores de escolas normais e professores primários, além da criação, produção, demonstração e adaptação de material didático. As novas orientações envolveram mudanças curriculares e metodológicas. Uma das mais importantes alterações foi a introdução do método global de alfabetização apresentado como solução para o problema dos baixos índices de aprendizagem da leitura e da escrita nas primeiras séries do curso primário. Além disso, foi introduzida a Matemática Moderna e os Estudos Sociais e a Iniciação às Ciências, matérias fundamentadas na integração e correlação dos 
conteúdos. Em relação à metodologia do ensino foram enfatizados o método de unidades didáticas (tratamento integrado do conhecimento e das experiências de ensino), a leitura de jornais, as exposições de criatividade, entre outras orientações didáticas (SOUZA, 2009).

Em relação aos cursos promovidos pelo CRPE/SP, encontramos em Lugli (2002) as seguintes referências: entre 1962 e 1968, foram ministrados sete Cursos de Especialização em Recursos Audiovisuais com a duração de um ano cada um. Nos anos de 1967 e 1968 foi ministrado o Curso sobre Materiais e Métodos Audiovisuais de Ensino; em 1970, o I Curso Interamericano de Comunicação Visual e o Curso de Especialização em Comunicação Visual. Além desses cursos, o Serviço de Recursos de Áudio Visuais (SRAV) promoveu em 1963 o I Curso de Especialistas em Recursos Audiovisuais, para o qual foram recrutados 16 educadores credenciados para a organização de Centros Regionais Audiovisuais procedentes de vários estados brasileiros (FORMANDO..., 1963, p. 3).

A promessa dos recursos audiovisuais era modificar as práticas pedagógicas, dando ênfase aos meios auxiliares do ensino. Teriam essas técnicas e meios adentrado os muros das escolas? Somente um conjunto de investimentos investigativos mais sistemáticos com vista ao exame aprofundado da apropriação desses recursos pelos professores poderá responder a questão. Por ora, podemos afirmar que os recursos audiovisuais contribuíram para deslocar o sentido dos objetos de ensino transformando o pressuposto da concreticidade para o encantamento pelas imagens.

Em síntese, a introdução de novos objetos de ensino fez parte de diferentes concepções pedagógicas ao longo do século XX. A persistência de culturas escolares, às vezes indiferentes, outras vezes seletivamente permeáveis a algumas dessas inovações, têm muito a dizer sobre o processo complexo de persistências e mudanças na educação.

\section{REFERÊNCIAS}

BIBLIOGRAFIA sobre Tecnologia Educacional 1970/1975. Revista Brasileira de Estudos Pedagógicos, Rio de Janeiro, v. 61, n. 138, p. 243-259, abr.jun. 1976.

BRASIL. Ministério da Educação e Saúde. Serviço de Estatística da Educação e Saúde. O ensino no Brasil em 1937. Rio de Janeiro: Serviço Gráfico do IBGE, 1943.

BUISSON, Ferdinand. Rapport sur L'Instruction Primaire à l'Exposition Universelle de Vienne en 1873. Paris: Imprimerie Nationale, 1875. 
FARIA, L. Situação atual dos audiovisuais no Brasil. Revista Brasileira de Estudos Pedagógicos, Rio de Janeiro, v. 61, n. 138, p. 262-264, abr./jun. 1976.

FERREIRA, M. S. O Centro Regional de Pesquisa Educacional de São Paulo (1956 1961). Dissertação (Mestrado em Educação) - Faculdade de Educação, Universidade de São Paulo, São Paulo, 2001.

FISCARELLI, R. B. O. Material didático: discursos e saberes. Araraquara: Junqueira \& Marin, 2008.

. A construção do saber sobre a utilização de objetos no ensino brasileiro. Tese (Doutorado em Educação Escolar) - Universidade Estadual Paulista, Araraquara, 2009.

FORMANDO líderes no campo audiovisual. Audiovisual em Revista, Rio de Janeiro, ano V, n. 15, 1963, p. 2-3.

HORTA, J. S. B. Rádio e educação no Brasil. Revista Brasileira de Estudos Pedagógicos, Rio de Janeiro, v. 59, n. 130, p. 454-468, abr./jun. 1973.

. Liberalismo, tecnocracia e planejamento educacional no Brasil: uma contribuição à história da educação brasileira no período de 1930-1970. São Paulo: Cortez/ Autores Associados, 1982.

KUHLMANN JUNIOR, M. As grandes festas didáticas: a educação brasileira e as exposições internacionais (1862 - 1922). Bragança Paulista: Editora da Universidade São Francisco, 2001.

LEVANTAMENTO do ensino primário (resultados relativos à escola). Pesquisa e Planejamento, São Paulo, ano IV, v. 4, p. 57-81, jun. 1960.

LUGLI, R. S. G. O trabalho docente no Brasil: o discurso dos Centros Regionais de Pesquisa Educacional e das entidades representativas do magistério (1950-1971). Tese (Doutorado em Educação) - Universidade de São Paulo, São Paulo, 2002.

MANIFESTO DOS PIONEIROS DA EDUCAÇÃO NOVA. Revista Brasileira de Estudos Pedagógicos, Brasília, v. 65, n. 150, p. 407-425, maio/ago. 1984.

MONTEIRO, Ana Nicolaça. O cinema educativo como inovação pedagógica na escola primária paulista: 1933-1944. 169 f. Dissertação (Mestrado em Educação) - Faculdade de Educação da Universidade de São Paulo, São Paulo, 2006.

PARRA, N. Metodologia dos recursos audiovisuais: estudo fundamentado na psicologia genética de Jean Piaget. São Paulo: Saraiva, 1974.

SANTOS, Lucíola L. C. P. O Mito da eficiência no ensino: estudo crítico da tecnologia educacional. Dissertação (Mestrado em Educação) - Universidade Federal de São Carlos, 1980.

SOUZA, Rosa F. de. Templos de civilização: a implantação da escola primária graduada no Estado de São Paulo: 1889-1910. São Paulo: Ed. UNESP, 1998. 
. Uma contribuição para a história da cultura material escolar. In: ALMEIDA, Jane S. (Org.). Profissão Docente e Cultura Escolar. São Paulo: Intersubjetiva, 2004.

. História da Cultura Material Escolar: um balanço inicial. In: BENCOSTTA, M. L. (Org.). Culturas escolares, saberes e práticas educativas: itinerários históricos. São Paulo: Cortez, 2007. p. 163-191.

. Alicerces da Pátria. História da escola primária no estado de São Paulo (18901976). Campinas: Mercado de Letras, 2009.

. Fernando de Azevedo e a reconstrução do sistema educacional de São Paulo em 1933: sentidos e alcances de um projeto de reforma. In: MIGUEL, Maria E. B.; VIDAL, Diana G.; ARAUJO, Jose C. S. (Org.). As manifestações da Escola Nova no Brasil (1920 - 1946). Uberlândia: EDUFU; Campinas: Autores Associados, 2011. p. 337-361.

VALDEMARIN, V. T. Estudando as lições de coisas. Estudo sobre os fundamentos filosóficos do método de ensino intuitivo. Campinas: Autores Associados, 2004a.

. Os sentidos e a experiência: professores, alunos e métodos de ensino. In:

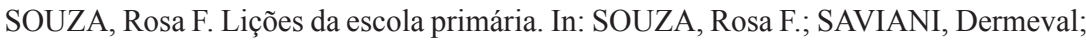
ALMEIDA, Jane S.; VALDEMARIN, Vera T. O legado educacional do século XX no Brasil. Campinas: Autores Associados, 2004b. p. 163-203.

. História dos métodos e materiais de ensino. A Escola Nova e seus modos de uso. São Paulo: Cortez, 2009.

VIDAL, D. G. Cinema, laboratórios, ciências físicas e Escola Nova. Cadernos de Pesquisa, São Paulo, n. 89, p. 24-28, maio 1994.

Texto recebido em 03 de dezembro de 2012.

Texto aprovado em 20 de fevereiro de 2013. 